Frontiers in Heat and Mass Transfer 2

\title{
NUMERICAL INVESTIGATION OF HEAT TRANSPORT IN A DIRECT METHANOL FUEL CELL WITH ANISOTROPIC GAS DIFFUSION LAYERS
}

\author{
Zheng Miao ${ }^{\mathrm{a}}$, Ya-Ling He ${ }^{\mathrm{a}}$, ${ }^{\text {Tian-Shou Zhao }}{ }^{\mathrm{b}}$, Wen-Quan Tao ${ }^{\mathrm{a}}$ \\ ${ }^{a}$ Key Laboratory of Thermal Fluid Science and Engineering of MOE, State Key Laboratory of Multiphase Flow in Power Engineering, School of \\ Energy and Power Engineering, Xi'an Jiaotong University, Xi'an, Shaanxi, 710049, P.R.China \\ ${ }^{b}$ Department of Mechanical Engineering, The Hong Kong University of Science and Technology, Clear Water Bay, Kowloon, Hong Kong, China
}

\begin{abstract}
A non-isothermal two-phase mass transport model is developed in this paper to investigate the heat generation and transport phenomena in a direct methanol fuel cell with anisotropic gas diffusion layers (GDLs). Thermal contact resistances at the GDL/CL (catalyst layer) and GDL/Rib interfaces, and the deformation of GDLs are considered together with the inherent anisotropy of the GDL. Latent heat effects due to condensation/evaporation of water and methanol between liquid and gas phases are also taken into account. Formulation of the two-phase mass transport across the membrane electrode assembly (MEA) is mainly based on the classical multiphase flow theory in the porous media. The numerical results show that the overall heat flux in MEA is mainly contributed to heat generation in anode and cathode CLs. And the anisotropic factors of the GDLs, including the inherent anisotropy, the spatially varying contact resistances, and the deformation of GDLs, have strong impacts on heat transport processes in the DMFC by altering the distribution of temperature across the MEA.
\end{abstract}

Keywords: direct methanol fuel cell; two-phase model; anisotropic; deformation; contact resistance

\section{INTRODUCTION}

The direct methanol fuel cells (DMFCs) are widely regarded as one of the most promising alternative power sources for the portable electronic devices (Dyer, 2002). In recent years, significant progress has been achieved in enhancing the cell performance. However, the practical application of DMFCs is still hindered by several technical challenges (Acres, 2001). Thermal management is one of the challenges. Thermal management has the vital importance for a stable and long time operation of the DMFC. Temperature is a very influential parameter in a working DMFC. Water evaporation/condensation between the liquid and vapor phases, electrochemical reaction rate, and transport coefficients of species are all very sensitive to temperature. The effective thermal management is aimed to prevent heat spots occurring in the MEA and, with the help of water management, maintain a stable and high performance of DMFC.

Extensive efforts have been devoted to the research of heat transport in PEMFC (Vie and Kjelstrup, 2004; Basu et al., 2006; Coppo et al., 2006; Matamoros and Bruggemann, 2006; Bapat and Thynell, 2007; Hottinen and Himanen, 2007; Pasaogullari et al., 2007; Ahmed et al., 2008; Ahmed et al., 2008; Bapat and Thynell, 2008; Nitta et al., 2008; Sadeghi et al., 2008; David et al., 2009; Ju, 2009). However, few open published literatures can be found focusing on heat transport phenomena in DMFC. Dohle et al., (2002) investigated heat and power management of a DMFC system. They found that the combinations of pressure and air flow rate were limited due to heat losses caused by water vaporization in the cathode at operating temperature above $90{ }^{\circ} \mathrm{C}$. Zhao and their co-workers (Chen and Zhao,2005; Chen et al., 2008) developed both one-dimensional and two-dimensional two-phase thermal model for passive-feed DMFCs. The results revealed that higher methanol concentrations lead to higher methanol crossover, and then the operating temperature becomes higher due to heat release of methanol oxidization reaction in cathode catalyst layer and brings an improved cell performance. Oliveira et al., (2008) presented a 1D model accounting for coupled heat and mass transfer. The model output is the temperature profile through the cell.

From the review of the above literatures, it can be seen that the research of heat transport in DMFC is insufficient. The heat generation and transport processes should be investigated more carefully by a sound mathematical model involving the important influential factors, such as methanol crossover, latent heat due to the non-equilibrium evaporation/condensation of water and methanol, and heat transfer mechanisms. Additionally, GDLs in DMFC are usually made of carbon paper or carbon cloth. The preferentially oriented carbon fibers make the GDL exhibiting significant anisotropy, represented by different transfer coefficients along the in-plane and through-plane directions (Yang et al., 2008). Compared to the inherent anisotropy, another anisotropy, the deformation of the GDL, was proved to have much greater effects on species and heat transport, as well as the cell performance (Nitta et al., 2006; Hottinen and Himanen, 2007; Hottinen et al., 2007; Nitta et al., 2008; Nitta et al., 2008; Nitta et al., 2008; Miao et al., 2010). Besides that, the thermal contact resistance at the GDL/Rib and GDL/CL interfaces also has great effects on temperature distribution in the MEA. As the thermal contact resistance is affected by the shape of the GDL, it is also treated as one kind of anisotropy in this paper.

\footnotetext{
* Corresponding author. Email: yalinghe@mail.xjtu.edu.cn
} 
The objective of this work is to investigate the heat generation and transport processes in the DMFC with anisotropic GDLs by numerical modeling. The present model is a further development from our former two-dimensional two-phase anisotropic model (Miao et al., 2010). Anisotropic heat transfer coefficients are used to capture a more realistic heat transport mechanism.

\section{MATHEMATICAL MODEL}

The mathematical model in this work is based on the classical liquid and gas two-phase flow theory for the porous media. Fig. 1 shows a two-dimensional periodic unit of a DMFC, which consists of anode flow channel (FC), anode DL, anode CL, polymer electrolyte membrane (PEM), cathode CL, cathode DL and cathode FC. The boundaries of the modeled geometry are marked by the Arabic numerals.

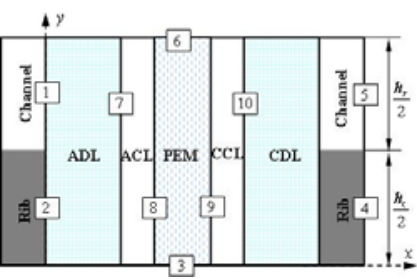

(a)

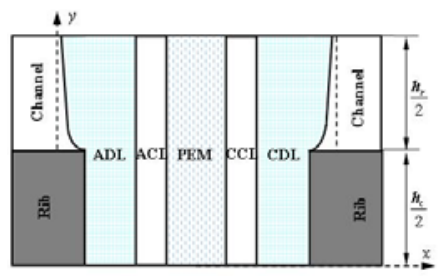

(b)
Fig. 1 Computational domain: (a) geometry of the GDL without deformation, (b) geometry of the deformed GDL.

\subsection{General governing equations}

In the present work, only a summary of the governing equations corresponding to the physical model in Fig. 1 is listed below. Details of the model have been described in our previous work (Miao et al., 2010).

\section{Solid and membrane phase potential}

$\frac{\partial}{\partial x}\left(\sigma_{\mathrm{m}, x} \frac{\partial \varphi_{\mathrm{m}}}{\partial x}\right)+\frac{\partial}{\partial y}\left(\sigma_{\mathrm{m}, y} \frac{\partial \varphi_{\mathrm{m}}}{\partial y}\right)=i_{\mathrm{m}}$

$\frac{\partial}{\partial x}\left(\sigma_{\mathrm{s}, x} \frac{\partial \varphi_{\mathrm{s}}}{\partial x}\right)+\frac{\partial}{\partial y}\left(\sigma_{\mathrm{s}, y} \frac{\partial \varphi_{\mathrm{s}}}{\partial y}\right)=i_{\mathrm{s}}$

\section{Pressure of liquid and gas phase}

$\frac{\partial}{\partial x}\left(-\frac{K_{x} \rho_{\mathrm{g}} k_{\mathrm{rg}}}{\mu_{\mathrm{g}}} \frac{\partial p_{\mathrm{g}}}{\partial x}\right)+\frac{\partial}{\partial y}\left(-\frac{K_{y} \rho_{\mathrm{g}} k_{\mathrm{rg}}}{\mu_{\mathrm{g}}} \frac{\partial p_{\mathrm{g}}}{\partial y}\right)=\dot{m}_{\mathrm{g}}$

$\frac{\partial}{\partial x}\left(-\frac{K_{x} \rho_{\mathrm{l}} k_{\mathrm{rl}}}{\mu_{1}} \frac{\partial p_{1}}{\partial x}\right)+\frac{\partial}{\partial y}\left(-\frac{K_{y} \rho_{\mathrm{l}} k_{\mathrm{rl}}}{\mu_{1}} \frac{\partial p_{1}}{\partial y}\right)=\dot{m}_{1}-\frac{n_{\mathrm{d}} M_{\mathrm{W}}}{F} i_{\mathrm{m}}$

\section{Velocities of liquid and gas phases}

$\mathbf{u}_{1}=-\left(\frac{K_{x} k_{\mathrm{rl}}}{\mu_{1}} \frac{\partial p_{1}}{\partial x}-\frac{n_{\mathrm{d}} M}{\rho_{1}} \frac{\mathrm{I}_{x}}{F}\right) \vec{e}_{x}-\left(\frac{K_{y} k_{\mathrm{rl}}}{\mu_{1}} \frac{\partial p_{1}}{\partial y}-\frac{n_{\mathrm{d}} M}{\rho_{1}} \frac{\mathrm{I}_{y}}{F}\right) \vec{e}_{y}$

$\mathbf{u}_{\mathrm{g}}=-\frac{K_{x} k_{\mathrm{rg}}}{\mu_{\mathrm{g}}} \frac{\partial p_{\mathrm{g}}}{\partial x} \vec{e}_{x}-\frac{K_{y} k_{\mathrm{rg}}}{\mu_{\mathrm{g}}} \frac{\partial p_{\mathrm{g}}}{\partial y} \vec{e}_{y}$

\section{Species conservation equations}

$$
\begin{aligned}
& \frac{\partial}{\partial x}\left(u_{1} C_{\mathrm{M}}\right)+\frac{\partial}{\partial y}\left(v_{1} C_{\mathrm{M}}\right)=\frac{\partial}{\partial x}\left(D_{\mathrm{M}, x}^{\mathrm{eff}} \frac{\partial C_{\mathrm{M}}}{\partial x}\right)+\frac{\partial}{\partial y}\left(D_{\mathrm{M}, y}^{\mathrm{eff}} \frac{\partial C_{\mathrm{M}}}{\partial y}\right)+\dot{R}_{\mathrm{M}} \\
& \frac{\partial}{\partial x}\left(u_{\mathrm{g}} C_{i, \mathrm{~g}}\right)+\frac{\partial}{\partial y}\left(v_{\mathrm{g}} C_{i, \mathrm{~g}}\right)=\frac{\partial}{\partial x}\left(D_{i, x}^{\mathrm{eff}} \frac{\partial C_{i, \mathrm{~g}}}{\partial x}\right)+\frac{\partial}{\partial y}\left(D_{i, y}^{\mathrm{eff}} \frac{\partial C_{i, \mathrm{~g}}}{\partial y}\right)+\dot{R}_{i, \mathrm{~g}}
\end{aligned}
$$

In order to calculate the latent heat of phase change, the nonequilibrium evaporation/condensation of water and methanol between liquid and vapor phases are considered here and involved in the source terms of Eqs. (7) and (8). The expressions of interfacial mass transfer rate of water and methanol are given bellow.

$\tilde{R}_{\mathrm{W}}= \begin{cases}k_{\mathrm{e}} \frac{\varepsilon s \rho_{1}}{M_{\mathrm{W}}}\left(p_{\mathrm{w}}^{\mathrm{sat}}-y_{\mathrm{WV}} p_{\mathrm{g}}\right), & p_{\mathrm{w}}^{\mathrm{sat}} \geq y_{\mathrm{WV}} p_{\mathrm{g}} \\ k_{\mathrm{c}} \frac{\varepsilon(1-s) y_{\mathrm{WV}}}{R T}\left(p_{\mathrm{w}}^{\mathrm{sat}}-y_{\mathrm{Wv}} p_{\mathrm{g}}\right), & p_{\mathrm{w}}^{\mathrm{sat}}<y_{\mathrm{Wv}} p_{\mathrm{g}}\end{cases}$

$\tilde{R}_{\mathrm{M}}=A_{\mathrm{lg}} h_{\mathrm{lg}} s(1 .-s) \frac{p_{\mathrm{MV}}^{\mathrm{sat}}-p_{\mathrm{MV}}}{R T}$

\section{Liquid saturation}

$$
\begin{aligned}
& \frac{\partial}{\partial x}\left(\frac{K_{x} \rho_{\mathrm{l}} k_{\mathrm{r} 1}}{\mu_{1}}\right)\left(\frac{\mathrm{d} p_{\mathrm{c}}}{\mathrm{d} s}\right) \frac{\partial s}{\partial x}+\frac{\partial}{\partial y}\left(\frac{K_{y} \rho_{\mathrm{l}} k_{\mathrm{rl}}}{\mu_{1}}\right)\left(\frac{\mathrm{d} p_{\mathrm{c}}}{\mathrm{d} s}\right) \frac{\partial s}{\partial y} \\
& =\dot{m}_{1}+\frac{n_{\mathrm{d}} M_{\mathrm{W}}}{F} i_{\mathrm{m}}-\frac{\rho_{\mathrm{l}} k_{\mathrm{rl}} \mu_{\mathrm{g}}}{\rho_{\mathrm{g}} k_{\mathrm{rg}} \mu_{1}} \dot{m}_{\mathrm{g}}
\end{aligned}
$$

where $p_{\mathrm{c}}$ is the capillary pressure. The expression of $p_{\mathrm{c}}$ is

$$
\begin{aligned}
& p_{\mathrm{c}}=p_{\mathrm{g}}-p_{1}=\sigma \cos \theta_{\mathrm{c}}(\varepsilon / K)^{0.5} J(s) \\
& J(s)= \begin{cases}1.417(1-s)-2.12(1-s)^{2}+1.263(1-s)^{3} & 0^{\circ} \leq \theta_{\mathrm{c}}<90^{\circ} \\
1.417 s-2.12 s^{2}+1.263 s^{3} & 90^{\circ} \leq \theta_{\mathrm{c}}<180^{\circ}\end{cases}
\end{aligned}
$$

Water content in the polymer In the PEM, water content can be derived from the equation below:

$\nabla \cdot\left(-\frac{\rho^{\mathrm{mem}}}{E W} D_{\mathrm{W}, \mathrm{N}}(\lambda) \nabla \lambda-\frac{\rho_{1}}{M_{\mathrm{w}}} \frac{K}{\mu_{1}} \nabla p_{1}+n_{\mathrm{d}, \mathrm{W}}(\lambda) \frac{I}{F}\right)=0$

In CLs, water content can be calculated by

$\lambda=s \lambda_{1}+(1-s) \lambda_{\mathrm{g}}$

where $\lambda_{1}$ and $\lambda_{\mathrm{g}}(\mathrm{Ju}, 2009)$ are water content of the polymer electrolyte in the CLs when the electrolyte phase is at the equilibrium state with liquid water and water vapor, respectively.

Energy conservation equation Heat transport process in the DMFC is modeled by the energy conservation equation as follows:

$$
\begin{aligned}
& \frac{\partial}{\partial x}\left(\rho_{\mathrm{g}} C_{\mathrm{p}, \mathrm{g}} u_{\mathrm{g}} T+\rho_{\mathrm{l}} C_{\mathrm{p}, \mathrm{l}} u_{1} T\right)+\frac{\partial}{\partial x}\left(\rho_{\mathrm{g}} C_{\mathrm{p}, \mathrm{g}} v_{\mathrm{g}} T+\rho_{\mathrm{l}} C_{\mathrm{p}, 1} v_{\mathrm{l}} T\right) \\
& =\frac{\partial}{\partial x}\left(\kappa_{x}^{\mathrm{eff}} \frac{\partial T}{\partial x}\right)+\frac{\partial}{\partial y}\left(\kappa_{y}^{\mathrm{eff}} \frac{\partial T}{\partial y}\right)+\dot{R}_{T}
\end{aligned}
$$

Terms at the left side of the equation represent the convection contribution of liquid and gas phase motion to the heat transport. The first and second terms at the right side of the equation consider the heat conduction process in the MEA. The last term in the right side: $\dot{R}_{T}$ is the heat generation rate in the DMFC and can be expressed as:

$\dot{R}_{T}=q_{\mathrm{act}}+q_{\mathrm{reac}}+q_{\mathrm{J}}+q_{\mathrm{c} / \mathrm{e}}$ 
where $q_{\text {act }}$ is irreversible heat release from the activation of the electrochemical reactions, $q_{\text {reac }}$ the reversible entropic heat loss from the half reactions, $q_{\mathrm{J}}$ Joule heating due to electrical and ionic resistances, and $q_{\mathrm{c} / \mathrm{e}}$ the heat source due to the non-equilibrium condensation/evaporation of water and methanol. When solving the energy conservation equation, according to heat generation mechanisms in different layers, the source terms are given as

ADL: $\quad \dot{R}_{T}=q_{\mathrm{J}}+q_{\mathrm{c} / \mathrm{e}}=\left|\mathbf{I}_{\mathrm{s}}\right|^{2} / \sigma_{\mathrm{s}}+h_{\mathrm{v}, \mathrm{W}} \dot{R}_{\mathrm{W}}+h_{\mathrm{v}, \mathrm{M}} \dot{R}_{\mathrm{M}}$

where $h_{\mathrm{v}, \mathrm{W}}$ and $h_{\mathrm{v}, \mathrm{M}}$ are evaporation heat of water and methanol.

$\mathbf{I}_{\mathrm{s}}$ is the local electron current density.

$$
\begin{aligned}
\dot{R}_{T}= & q_{\mathrm{act}}+q_{\mathrm{reac}}+q_{\mathrm{J}}+q_{\mathrm{c} / \mathrm{e}} \\
\text { ACL }: \quad & i_{\mathrm{a}}\left(\eta_{\mathrm{a}}-\left(\Delta H_{\mathrm{a}}-\Delta G_{\mathrm{a}}\right) / 6 F\right)+\left|\mathbf{I}_{\mathrm{s}}\right|^{2} / \sigma_{\mathrm{s}}+\left|\mathbf{I}_{\mathrm{m}}\right|^{2} / \sigma_{\mathrm{m}} \\
& +h_{\mathrm{v}, \mathrm{W}} \dot{R}_{\mathrm{W}}+h_{\mathrm{v}, \mathrm{M}} \dot{R}_{\mathrm{M}}
\end{aligned}
$$

where $\mathbf{I}_{\mathrm{m}}$ denotes the ionic local current density in the electrolyte phase.

$$
\begin{aligned}
\text { PEM: } \quad \dot{R}_{T}= & q_{\mathrm{J}}=\left|\mathbf{I}_{\mathrm{m}}\right|^{2} / \sigma_{\mathrm{m}} \\
\dot{R}_{T}= & q_{\mathrm{act}}+q_{\mathrm{reac}}+q_{\mathrm{J}}+q_{\mathrm{c} / \mathrm{e}} \\
\text { CCL: } \quad= & \left(i_{\mathrm{c}}-i_{\mathrm{p}}\right)\left(\eta_{\mathrm{c}}-\left(\Delta H_{\mathrm{c}}-\Delta G_{\mathrm{c}}\right) / 4 F\right)-i_{\mathrm{p}} \Delta H / 6 F+\left|\mathbf{I}_{\mathrm{s}}\right|^{2} / \sigma_{\mathrm{s}} \\
& +\left|\mathbf{I}_{\mathrm{m}}\right|^{2} / \sigma_{\mathrm{m}}+h_{\mathrm{v}, \mathrm{W}} \dot{R}_{\mathrm{W}}+h_{\mathrm{v}, \mathrm{M}} \dot{R}_{\mathrm{M}}
\end{aligned}
$$

The second term at the right side of Eq. (21) represents the heat release due to methanol crossover.

CDL: $\quad \dot{R}_{T}=q_{\mathrm{J}}+q_{\mathrm{c} / \mathrm{e}}=\left|\mathbf{I}_{\mathrm{s}}\right|^{2} / \sigma_{\mathrm{s}}+h_{\mathrm{v}, \mathrm{W}} \dot{R}_{\mathrm{W}}$

\subsection{Electrochemical kinetics}

The multi-step mechanism of methanol oxidation reaction (MOR) (Nordlund and Lindbergh, 2002; Liu and Wang, 2007) used in our former work (Miao et al., 2010) is also used in the present model to calculate the MOR rate in the ACL:

$i_{\mathrm{a}}=6 a F K k_{4} \exp \left(\frac{\left(1-\beta_{4}\right) F\left(\varphi_{\mathrm{s}, \mathrm{a}}-\varphi_{\mathrm{m}, \mathrm{a}}\right)}{R T}\right) \theta_{\mathrm{CO}} \theta_{\mathrm{OH}}$

Detailed expressions of coefficients used in Eq. (23) can be found in (Miao et al., 2010). In the CCL, the local reaction rate of oxygen reduction reaction (ORR) can be given as:

$i_{\mathrm{c}}=(1-s) A_{\mathrm{i}} i_{\mathrm{O}_{2}}^{\mathrm{ref}}\left(\frac{C_{\mathrm{O}_{2}}}{C_{\mathrm{O}_{2}}^{\text {ref }}}\right) \exp \left[\frac{\alpha_{\mathrm{c}} F}{R T}\left(V_{0}+\varphi_{\mathrm{m}, \mathrm{c}}-\varphi_{\mathrm{s}, \mathrm{c}}\right)\right] \xi_{\mathrm{O}_{2}}$

where $\xi_{\mathrm{O}_{2}}$ is the correction factor derived from the modified agglomerate model (Miao et al., 2008), and represents the effect of the mass transfer resistance of oxygen in the agglomerate and its Nafion coating.

Methanol crossover is an important aspect of mass transport phenomena in DMFC. The flux of methanol crossover can be determined by
$N_{\text {cross }}=-D_{\mathrm{M}, \mathrm{N}} \nabla C_{\mathrm{M}}+n_{\mathrm{d}, \mathrm{M}} \frac{I}{F}-\left(\frac{K_{\mathrm{mem}}}{\mu_{1}} \frac{\Delta p_{1}}{l_{\mathrm{mem}}}\right) C_{\mathrm{M}}$

Then, the parasitic current density in the CCL due to total oxidization of methanol crossover through the PEM can be given as

$I_{\mathrm{p}}=6 F N_{\text {cross }}$

In a operating DMFC, the anode and cathode current density can be obtained by

$I_{\mathrm{a}}=\left(\iint_{\mathrm{ACL}} i_{\mathrm{a}} \mathrm{d} x \mathrm{~d} y\right) /\left(h_{\mathrm{c}}+h_{\mathrm{r}}\right)$
$I_{\mathrm{c}}=\left(\iint_{\mathrm{CCL}} i_{\mathrm{c}} \mathrm{d} x \mathrm{~d} y\right) /\left(h_{\mathrm{c}}+h_{\mathrm{r}}\right)$

So the current balance of the fuel cell is expressed as

$I_{\text {Cell }}=I_{\mathrm{a}}=I_{\mathrm{c}}-I_{\mathrm{p}}$

Up to this point, all the governing equations and correlations related to the mass and heat transport in fuel cell and electrochemical reactions have been presented. Detailed expressions of source terms and correlations of several coefficients are listed in Table 1.

\subsection{Boundary conditions}

At the corresponding computational domains, 10 boundary conditions need to be specified. As the computational domain is half of a periodic unit of the fuel cell, the symmetrical conditions for all variables are given at boundary 3 and 6 . Inlet conditions are specified at boundary 1 and 5 where are the inlets of reactants in the anode and cathode FC/GDL interfaces respectively. Temperatures at boundary 2 and 4 keep constant while isothermal boundary conditions are applied at boundary 1 and 5 . Other interfacial conditions in the computational domain are given based on the principle of balance of mass, charges and heat flux at these interfaces. The detailed information of boundary conditions can be found in our former work (Miao et al., 2010).

\section{NUMERICAL RESULTS AND DISCUSSION}

All the governing equations given in Section 2 are solved by a self-written computer code based on the finite-volume-method. Note that the mesh independence of the model has been checked and the validation of the two-phase transport model can be found elsewhere (Miao et al., 2008). The baseline conditions of this model are listed in Table 2. And parameters and correlations are given in Table 3. Some parameters are picked from the open published works (Yang and Zhao, 2007; Um et al., 2000; Wang and Wang, 2003; Song et al., 2004; Divisek et al., 2003; Wang et al., 2004; Murgia et al., 2003; Meng, 2006; He et al., 2009).

\subsection{Temperature distribution}

In order to investigate the anisotropic factors of heat transport processes separately, three cases of GDLs are studied in the present work. Isotropic GDL: the GDL is treated as a both homogeneous and isotropic porous medium. The through-plane transport coefficients for mass, electrons and heat are used for numerical calculation along both 
Table 1. Expressions of source terms and coefficients of the governing equations.

\begin{tabular}{|c|c|}
\hline Parameters & Expressions \\
\hline Generation rate of charges & $i_{\mathrm{m}}=\left\{\begin{array}{ll}i_{\mathrm{a}} & \mathrm{ACL} \\
i_{\mathrm{c}}-i_{\mathrm{p}} & \mathrm{CCL}\end{array}, i_{\mathrm{s}}= \begin{cases}-i_{\mathrm{a}} & \mathrm{ACL} \\
i_{\mathrm{p}}-i_{\mathrm{c}} & \mathrm{CCL}\end{cases} \right.$ \\
\hline $\begin{array}{l}\text { Mole generation rate of } \\
\text { species }\end{array}$ & $\dot{R}_{\mathrm{M}}=\left\{\begin{array}{ll}-i_{\mathrm{a}} /(6 F) & \mathrm{ACL} \\
-\tilde{R}_{\mathrm{M}} & \mathrm{ADL}\end{array}, \dot{R}_{\mathrm{O}_{2}}=\left\{\begin{array}{ll}-i_{\mathrm{c}} /(4 F) & \mathrm{CCL} \\
0 & \mathrm{CDL}\end{array}, \dot{R}_{\mathrm{MV}}=\left\{\begin{array}{ll}\tilde{R}_{\mathrm{M}} & \mathrm{ACL} \\
\tilde{R}_{\mathrm{M}} & \mathrm{ADL}\end{array}, \dot{R}_{\mathrm{WV}}=\left\{\begin{array}{ll}\tilde{R}_{\mathrm{W}} & \mathrm{CLs} \\
\tilde{R}_{\mathrm{W}} & \mathrm{GDLs}\end{array}, \dot{R}_{\mathrm{CO}_{2}}= \begin{cases}i_{\mathrm{a}} /(6 F) & \mathrm{ACL} \\
i_{\mathrm{p}} /(6 F) & \mathrm{CCL}\end{cases} \right.\right.\right.\right.$ \\
\hline $\begin{array}{l}\text { Generation rate of mass in gas } \\
\text { and liquid phase }\end{array}$ & $\dot{m}_{\mathrm{g}}=\left\{\begin{array}{ll}M_{\mathrm{W}} \tilde{R}_{\mathrm{W}}+M_{\mathrm{M}} \tilde{R}_{\mathrm{MV}} & \mathrm{ADL} \\
M_{\mathrm{W}} \tilde{R}_{\mathrm{W}}+M_{\mathrm{M}} \tilde{R}_{\mathrm{MV}}+M_{\mathrm{CO}_{2}} \tilde{R}_{\mathrm{CO}_{2}} & \mathrm{ACL} \\
M_{\mathrm{W}} \tilde{R}_{\mathrm{W}}-M_{\mathrm{O}_{2}} \tilde{R}_{\mathrm{O}_{2}}+M_{\mathrm{CO}_{2}} \tilde{R}_{\mathrm{CO}_{2}} & \mathrm{CCL} \\
M_{\mathrm{W}} \tilde{R}_{\mathrm{W}} & \mathrm{CDL}\end{array}, \dot{m}_{1}=-\dot{m}_{\mathrm{g}}\right.$ \\
\hline Relative permeability & $k_{\mathrm{rl}}=s^{3}, \quad k_{\mathrm{rg}}=(1-s)^{3}$ \\
\hline $\begin{array}{l}\text { Thickness of the GDL under } \\
\text { inhomogeneous compression }\end{array}$ & $L(y)=\left\{\begin{array}{l}L_{\text {comp }}=2.5 \times 10^{-4} \mathrm{~m} \\
19.30314 \log \left((y-0.0005) \times 10^{6}+1\right) \times 10^{-6}+L_{\text {comp }}\end{array}\right.$ \\
\hline $\begin{array}{l}\text { Porosity of the GDL under } \\
\text { inhomogeneous compression }\end{array}$ & $\varepsilon(y)=\varepsilon_{0}\left(L(y)-L_{\min }\right) /\left(L_{0}-L_{\min }\right), \quad L_{\min }=L_{0} \times\left(1 .-\varepsilon_{0}\right)$ \\
\hline In-plane permeability & $K_{\text {in-p }}=2.754 L(y)^{3}-1.484 \times 10^{-3} L(y)^{2}+2.76 \times 10^{-7} L(y)-1.7 \times 10^{-11}$ \\
\hline $\begin{array}{l}\text { Electrical conductivity of the } \\
\text { GDL }\end{array}$ & $\sigma_{\text {in-p }}=-1.159 \times 10^{7} L(y)+6.896 \times 10^{3}, \sigma_{\text {th-p }}=-8.385 \times 10^{6} L(y)+3.285 \times 10^{3}$ \\
\hline $\begin{array}{l}\text { Interfacial electrical contact } \\
\text { resistance }\end{array}$ & $\begin{array}{l}r_{\mathrm{e}, \mathrm{GDL} / \mathrm{CL}}=5.83 \times 10^{-10} \exp \left(2.06 \times 10^{4} L(y)\right) \\
r_{\mathrm{e}, \mathrm{Rib} / \mathrm{GDL}}=1 . \times 10^{-9}\left(7.726 \times 10^{11} L(y)^{3}-4.943 \times 10^{8} L(y)^{2}+2.664 \times 10^{4} L(y)+18.911\right)^{-1}\end{array}$ \\
\hline $\begin{array}{l}\text { Interfacial thermal contact } \\
\text { resistance }\end{array}$ & $r_{T, \mathrm{Rib} / \mathrm{GDL}}=1 . \times 10^{-9}\left(\begin{array}{l}-2.912 \times 10^{14} L(y)^{4}+3.133 \times 10^{11} L(y)^{3} \\
-1.17 \times 10^{8} L(y)^{2}+1.639 \times 10^{4} L(y)-0.438\end{array}\right)^{-1}, r_{T, \mathrm{GDL} / \mathrm{CL}}=r_{T, \mathrm{Rib} / \mathrm{GDL}}$ \\
\hline
\end{tabular}

through-plane and in-plane directions. Anisotropic GDL: the GDL is homogeneous but anisotropic. Through-plane and in-plane coefficients are adopted differently for the through-plane and in-plane directions. Deformed GDL: the GDL is an anisotropic porous medium with deformation. The deformation effected through-plane and in-plane coefficients are used. Nitta et al., (2008) pointed out that the compression pressure has little effect on the thermal conductivity of GDL. So in this paper, the through-plane thermal conductivity of the GDLs is maintained at $1.18 \mathrm{~W} \mathrm{~m}-1 \mathrm{~K}-1$, obtained from their experimental study. And the in-plane thermal conductivity is kept as 10 times larger than the through-plane conductivity.

Temperature distributions across the MEA with (a) isotropic GDL, (b) anisotropic GDL, and (c) deformed GDL are shown in Fig. 2. It can be seen that the highest temperature appears in the region of CCL under the channel and adjacent to the PEM. These results qualitatively agree well with temperature distribution predicted by Oliveira et al., (2008). This reflects that the heat generation rate in this region is higher when the fuel cell works at $0.2 \mathrm{~V}$, near the limiting current density. Comparing these three figures, we can find that the case of isotropic GDL shows the largest temperature variation while the deformed GDL gives the smallest. This is because the isotropic GDL has the largest thermal resistance. In the anisotropic GDL, the in-plane thermal conductivity is 10 times larger than the through-plane thermal conductivity. Thus, the variation of temperature along in-plane direction becomes much smaller. And the temperature range across the MEA is reduced to $0.45 \mathrm{~K}$, compared with $0.9 \mathrm{~K}$ for the isotropic GDL. When the GDL is under inhomogeneous compression, the deformation of the GDL reduces the length of heat transfer path, and this also leads to a decrease in temperature variation range. The variation of temperature across the MEA for the case of deformed GDL is $0.3 \mathrm{~K}$. So we can see that the inherent anisotropy of the GDL and deformation of GDL in assembly work are favorable to thermal management in the DMFC.
Table 2. Cell geometric dimensions and base case of the model.

\begin{tabular}{|c|c|c|}
\hline Parameters/Symbols & Value & Unit \\
\hline \multicolumn{3}{|l|}{ Structure Parameters } \\
\hline \multicolumn{3}{|l|}{ Porosity, thickness } \\
\hline $\mathrm{GDL}, \varepsilon_{\mathrm{GDL}}, l_{\mathrm{GDL}}$ & $0.75, \quad 3.8 \times 10^{-4}$ &,$- \mathrm{m}$ \\
\hline $\mathrm{CL}, \quad \varepsilon_{\mathrm{cl}}, l_{\mathrm{cl}}$ & $0.3, \quad 0.2 \times 10^{-4}$ &,$- \mathrm{m}$ \\
\hline $\mathrm{PEM}, \varepsilon_{\mathrm{mem}}, l_{\mathrm{mem}}$ & $0.3,1.3 \times 10^{-4}$ &,$- \mathrm{m}$ \\
\hline Height of a half rib, $h_{\mathrm{r}}$ & $0.5 \times 10^{-3}$ & $\mathrm{~m}$ \\
\hline Height of a half channel, $h_{c}$ & $0.5 \times 10^{-3}$ & $\mathrm{~m}$ \\
\hline Length of channels, $L_{\mathrm{c}}$ & $3 \times 10^{-2}$ & $\mathrm{~m}$ \\
\hline \multicolumn{3}{|l|}{ Operation Conditions } \\
\hline Operation temperature, $T$ & 348.15 & $\mathrm{~K}$ \\
\hline $\begin{array}{l}\text { Anode and cathode channel } \\
\text { inlet pressure, } p_{1, a}^{\text {in }}, p_{\mathrm{g}, \mathrm{c}}^{\text {in }}\end{array}$ & 101325,101325 & $\mathrm{p}_{\mathrm{a}}$ \\
\hline $\begin{array}{l}\text { Inlet methanol concentration } \\
\text { at anode, } C_{\mathrm{M}}^{\text {in }}\end{array}$ & 1000 & $\mathrm{~mol} \mathrm{~m}^{-3}$ \\
\hline $\begin{array}{l}\text { Inlet oxygen concentration at } \\
\text { cathode, } C_{\mathrm{O}_{2}}^{\text {in }}\end{array}$ & 7.68 & $\mathrm{~mol} \mathrm{~m}^{-3}$ \\
\hline
\end{tabular}

Figure 3 gives the polarization curves of DFMC and the highest temperature for various current density in the DMFC with different type of GDLs. Because of the reduction of species transport coefficient due to deformation of the GDL, the limiting current density for the case of deformed GDL is smaller than the other two cases. In Fig. 3, it is seen that when the fuel cell is working in the current density range covering the activation polarization region and the Ohmic polarization region, the highest temperature of the DMFC is approximately a linear 
function of the cell current density. And in the concentration polarization region, temperature increases more rapidly. This is because the significant decrease in cell voltage near the limiting current density leads to the rapid increase in activation heat generation of the electrochemical reaction under a higher overpotential. The profiles of the highest temperature in the MEA indicate that heat generation in the MEA mainly depends on electrochemical reactions in the CLs. Besides the heat generation of MOR and ORR in CLs, another important factor of heat generation that should be considered in DMFC operation is the methanol crossover.

Table 3 Physicochemical properties and parameters used in simulation.

\begin{tabular}{|c|c|c|c|}
\hline Parameters & Symbols & Value & Unit \\
\hline \multicolumn{4}{|l|}{ Physicochemical properties } \\
\hline Conductivity in membrane phase & $\sigma_{\mathrm{m}}$ & $(0.5139 \lambda-0.326) \mathrm{e}^{[1268(1 / 303-1 / T)]}$ & $\Omega^{-1} \cdot \mathrm{m}^{-1}$ \\
\hline Conductivity in CLs & $\sigma_{\mathrm{cl}}$ & 300 & $\Omega^{-1} \cdot \mathrm{m}^{-1}$ \\
\hline \multicolumn{4}{|l|}{ permeability } \\
\hline $\mathrm{ADL}$ & $K_{\text {th-p }}$ & $3.74 \times 10^{-11}$ & $\mathrm{~m}^{2}$ \\
\hline CLs & $K_{\mathrm{cl}}$ & $1 \times 10^{-14}$ & $\mathrm{~m}^{2}$ \\
\hline PEM & $K_{\text {mem }}$ & $5 \times 10^{-18}$ & $\mathrm{~m}^{2}$ \\
\hline Viscosity of gas phase & $\mu_{\mathrm{g}}$ & $2.03 \times 10^{-5}$ & $\mathrm{~kg} \mathrm{~m}^{-1} \mathrm{~s}^{-1}$ \\
\hline Viscosity of liquid phase & $\mu_{1}$ & $4.06 \times 10^{-4}$ & $\mathrm{~kg} \mathrm{~m}^{-1} \mathrm{~s}^{-1}$ \\
\hline Electro-osmotic coefficients of water & $n_{\mathrm{d}}$ & $\frac{2.5 \lambda}{22}$ & \\
\hline \multicolumn{4}{|l|}{ Diffusivities } \\
\hline Methanol in liquid water & $D_{\mathrm{M}, 1}$ & $10^{-5.4163-999.778 / T}$ & $\mathrm{~m}^{2} \mathrm{~s}^{-1}$ \\
\hline Methanol in Nafion & $D_{\mathrm{M}, \mathrm{N}}$ & $4.9 \times 10^{-10} e^{[2436(1 / 333-1 / T)]}$ & $\mathrm{m}^{2} \mathrm{~s}^{-1}$ \\
\hline Methanol vapor in gas & $D_{\mathrm{MV}, \mathrm{g}}$ & $-6.954 \times 10^{-6}+4.5986 \times 10^{-8} T+9.4979 \times 10^{-11} T^{2}$ & $\mathrm{~m}^{2} \mathrm{~s}^{-1}$ \\
\hline Oxygen in gas phase & $D_{\mathrm{O}_{2}, \mathrm{~g}}$ & $1.775 \times 10^{-5}(T / 273.15)^{1.823}$ & $\mathrm{~m}^{2} \mathrm{~s}^{-1}$ \\
\hline Oxygen in Nafion & $D_{\mathrm{O}_{2}, \mathrm{~N}}$ & $1.844 \times 10^{-10}$ & $\mathrm{~m}^{2} \mathrm{~s}^{-1}$ \\
\hline Water in membrane & $D_{\mathrm{W}}^{\mathrm{mem}}$ & $4.17 \times 10^{-8} \lambda\left(161 \mathrm{e}^{-\lambda}+1\right) \mathrm{e}^{-2436 / T}$ & $\mathrm{~m}^{2} \mathrm{~s}^{-1}$ \\
\hline Water vapor in gas & $D_{\mathrm{WV}, \mathrm{g}}$ & $2.56 \times 10^{-5}(T / 307.15)^{2.334}$ & $\mathrm{~m}^{2} \mathrm{~s}^{-1}$ \\
\hline Interfacial transfer rate constant for methanol & $h_{\lg }$ & 0.001 & $\mathrm{~m}^{2} \mathrm{~s}^{-1}$ \\
\hline Specific interfacial area between liquid and gas & $A_{\mathrm{lg}}$ & $1 \times 10^{5}$ & $\mathrm{~m}^{-1}$ \\
\hline Henry law constant for methanol & $k_{\mathrm{H}, \mathrm{M}}$ & $0.096 e^{0.04511(T-273)}$ & atm \\
\hline Henry law constant for oxygen & $k_{\mathrm{H}}$ & $0.3125 \times 101325 /(R T)$ & \\
\hline Saturation pressure of vapor & $\log _{10} p_{\mathrm{W}}^{\mathrm{sat}}$ & $\begin{array}{l}-2.1794+0.02953(T-273)-9.1837 \times 10^{-5}(T-273)^{2} \\
+1.4454 \times 10^{-7}(T-273)^{3}\end{array}$ & atm \\
\hline Evaporation rate constant of water & $k_{\mathrm{e}}$ & $5 \times 10^{-3}$ & $\operatorname{atm}^{-1} \mathrm{~s}^{-1}$ \\
\hline Condensation rate constant of water & $k_{\mathrm{c}}$ & 50 & $\mathrm{~s}^{-1}$ \\
\hline \multicolumn{4}{|l|}{ Mole enthalpy change } \\
\hline Anode semi-reaction & $\Delta H_{\mathrm{a}}$ & 126.69 & $\mathrm{~kJ} \mathrm{~mol}^{-1}$ \\
\hline Cathode semi-reaction & $\Delta H_{\mathrm{c}}$ & -567.41 & $\mathrm{~kJ} \mathrm{~mol}^{-1}$ \\
\hline Overall reaction & $\Delta H$ & -724.43 & $\mathrm{~kJ} \mathrm{~mol}^{-1}$ \\
\hline $\begin{array}{l}\text { Mole Gibbs free energy change of the anode } \\
\text { semi-reaction }\end{array}$ & $\Delta G_{\mathrm{a}}$ & 9.35 & $\mathrm{~kJ} \mathrm{~mol}^{-1}$ \\
\hline $\begin{array}{l}\text { Mole Gibbs free energy change of the cathode } \\
\text { semi-reaction }\end{array}$ & $\Delta G_{\mathrm{c}}$ & -474.16 & $\mathrm{~kJ} \mathrm{~mol}^{-1}$ \\
\hline \multicolumn{4}{|l|}{ Electrochemical kinetics parameters } \\
\hline Exchange current density of ORR & $i_{\mathrm{O}_{2}}^{\mathrm{ref}}$ & $0.04222 e^{(73200 \times(1 / 353-1 / T) / R)}$ & $\mathrm{A} \mathrm{m}^{-3}$ \\
\hline Reference concentration of oxygen & $C_{\mathrm{O}_{2}}^{\mathrm{ref}}$ & $p_{\mathrm{O}_{2}} / R T$ & $\mathrm{~mol} \mathrm{~m}^{-3}$ \\
\hline Transfer coefficient of cathode & $\alpha_{\mathrm{c}}$ & 1.0 & \\
\hline Thermodynamic voltage & $V_{0}$ & 1.21 & V \\
\hline
\end{tabular}

Figure 4 shows the parasitic current density due to methanol crossover in the DMFC with different GDLs. A rapid decrease in methanol crossover with the increase of cell current density can be seen in Fig. 4. It can be deduced that methanol crossover mainly impacts the heat generation at a small current density. The detailed analysis of the mechanism of heat generation in DMFC will be presented in the following section. 


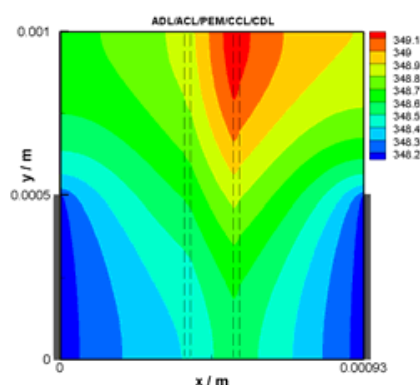

(a)

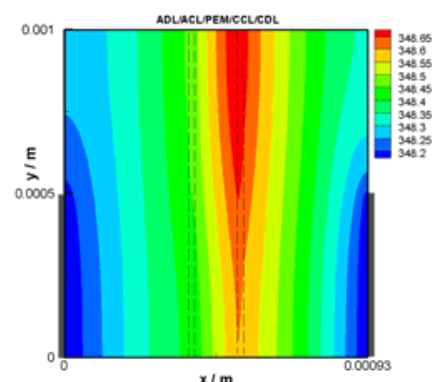

(b)

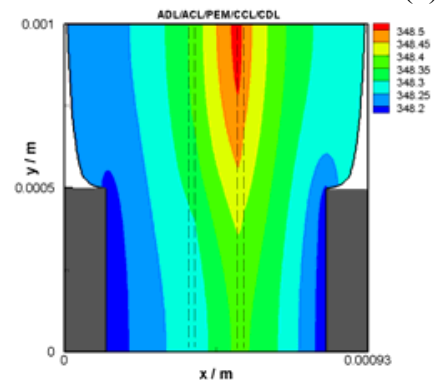

(c)

Fig. 2 Temperature distributions in the MEA with (a) isotropic GDL, (b) anisotropic GDL and (c) deformed GDL (cell voltage: $0.2 \mathrm{~V}$ )

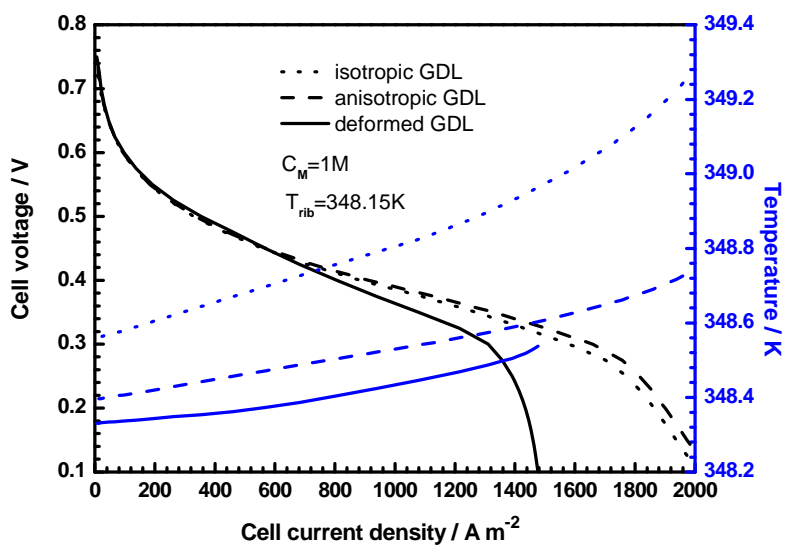

Fig. 3 Polarization curve and the highest temperature at various cell current density for DMFC with different GDL type.

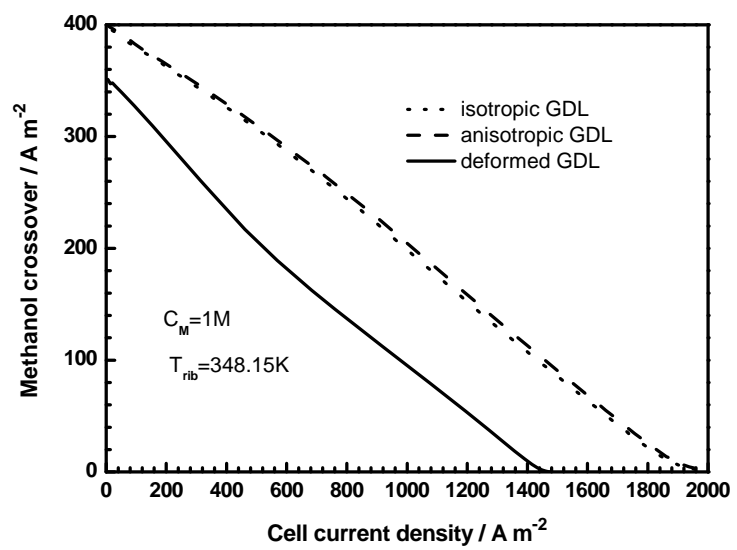

Fig. 4 Methanol crossover for DMFC with different GDL type.

A considerable amount of wasted heat will be produced when the fuel cells do electrical work (Pasaogullari et al., 2007). The predicted energy conversion efficiency along with cell power density at various cell current densities are presented in Fig. 5. For PEMFC the energy conservation efficiency is about $50 \%$. From Fig. 5, it is shown that the energy conservation efficiency for a DMFC is even smaller. The highest efficiency is about $27 \%$ for the case of deformed GDL. The smaller efficiency of DMFC is considered to be caused by the methanol crossover and even severer activation polarization in the anode CL. The numerical results in Fig. 5 are qualitatively in good agreement with the energy utilization analysis of the DMFC done by Li et al., (2008).

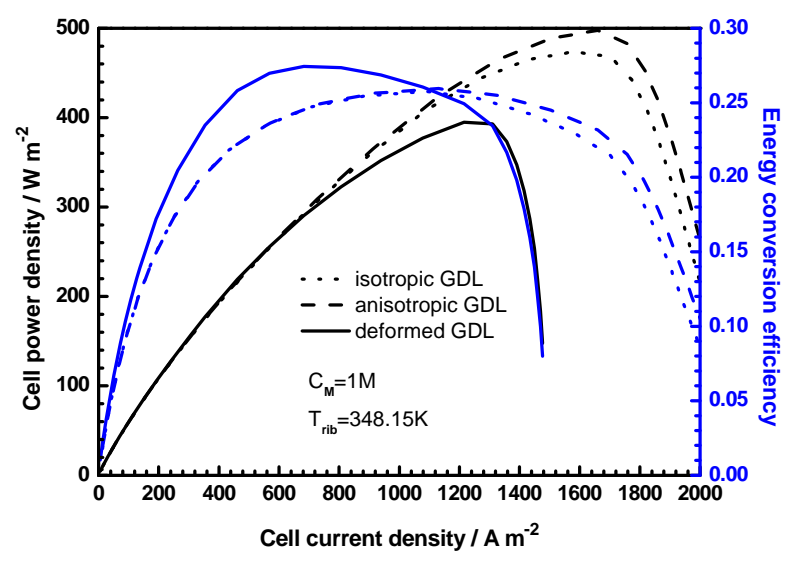

Fig. 5 Cell power density and fuel utilization ratio for DMFC with different GDL type.

\subsection{Analysis of heat generation mechanism}

In the present work, thermal management in DMFC is discussed at two aspects: heat generation mechanism and heat transport mechanism. The overall heat generation rate versus current density and the effect of methanol crossover are discussed in Section 3.1. And the detailed analysis of heat generation mechanism in DMFC is presented as follows.

Figure 6 shows the local heat generation rate through out the MEA at the cell voltages of $0.7 \mathrm{~V}$ and $0.2 \mathrm{~V}$. Generally speaking, most of heat generation occurs in the anode and cathode CL. In other layers of the MEA, GDLs and PEM, heat generation rates are much smaller. In these layers, heat is generated from transport processes of electrons and ions, and the evaporation and condensation of methanol and water. By comparing Fig. 6 (a) with Fig. 6 (b), it can be found that the increase in cell current density leads to increase in local heat generation rate. The highest local heat generation rate occurs in CCL. And the highest local heat generation rate at $0.2 \mathrm{~V}$ is about 3 times higher than that at $0.7 \mathrm{~V}$. It is noted that the local heat generation in ACL is transformed from a heat sink to heat source as the cell voltage decreases from $0.7 \mathrm{~V}$ to $0.2 \mathrm{~V}$.

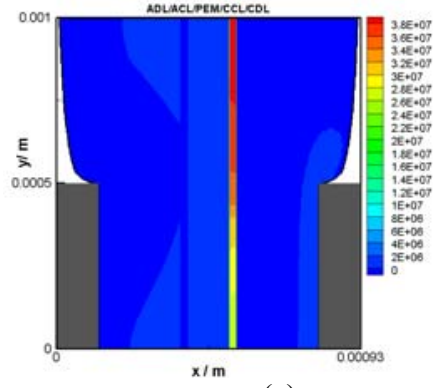

(a)

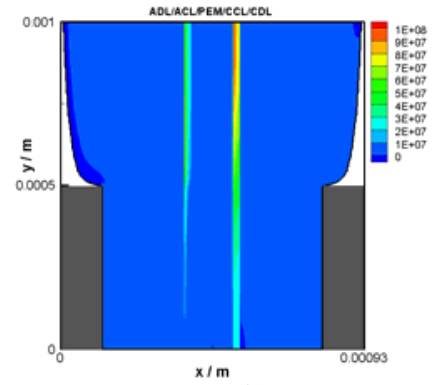

(b)
Fig. 6 Distribution of local heat generation rate in the MEA at (a) $0.7 \mathrm{~V}$ and (b) $0.2 \mathrm{~V}$.

In order to get a deep understanding of heat generation in CLs, the portions of several contributions to overall heat generation in anode $\mathrm{CL}$ and cathode CL are presented in Fig. 7 and Fig. 8. Heat generation in anode CL consists of five contributions (following the legend in Fig. 7): irreversible and reversible heat release from the anode half-reaction (MOR), ion transport, electron transport, methanol 
evaporation/condensation, and water evaporation/condensation. It is known that the MOR in anode CL is endothermic, so the reversible heat release from MOR is negative. And due to the much lower overpotential in anode CL when cell voltage is high, the irreversible heat flux generated by activation of MOR is quite small. Thus, as a sum of the irreversible and reversible heat, heat generation rate from MOR in anode CL is negative when the cell voltage of the DMFC is high, 0.6 and $0.7 \mathrm{~V}$ in Fig. 7 . With the decrease in cell voltage, the heat flux by activation of MOR increases sharply. Thus, the heat generation rate in anode CL becomes positive. When the cell voltage is low, most of heat is generated from heat release by MOR. Heat generation from other 4 mechanisms: transport processes of electrons and ions, evaporation and condensation of methanol and water, only contributes a much small portion of the overall heat flux in anode CL.

Attention is now turned to the heat generation in cathode CL. It includes 5 mechanisms: heat release from cathode half-reaction, methanol crossover, ion transport, electron transport, and evaporation and condensation of water. Heat generation rate in cathode CL in Fig. 8 shows that most of overall heat flux is contributed to two mechanisms: the heat release from half-reaction in cathode, and heat generation from oxidization of methanol crossover from anode CL to cathode CL. At a high cell voltage, the heat generation from methanol crossover contributes to more than a half of the overall heat flux. As the cell voltage becomes lower, methanol crossover decreases rapidly, as shown in Fig. 4. So heat generation from methanol crossover decreases. However, the reduction of cell voltage leads to a significant increase in the heat release from half-reaction in cathode $\mathrm{CL}$, which includes the reversible heat release from the exothermic half-reaction and irreversible heat release by activation of half-reaction in cathode CL. As a result of the combined effects of heat release from half-reaction and heat generation from methanol crossover, the overall heat flux in cathode CL increases sharply. Similar to the heat flux in anode CL, other three mechanisms of heat generation only contribute a very tiny portion of the overall heat flux in cathode CL.

\subsection{Analysis of heat transport mechanism}

The anisotropy of GDLs in DMFC that affects the heat transport processes mainly consists of two aspects: the anisotropic thermal conductivities of GDLs and the thermal contact resistance at the GDL/CL interface and the Rib/GDL interface. Fig. 9 shows the effect of in-plane thermal conductivity on temperature distribution in the anode and cathode CLs. It can be seen that, with the increase in inplane thermal conductivity, the highest temperature decreases and the profile of temperature in both anode and cathode CL becomes more uniform. This is because the lower thermal resistance facilitates the heat transport along the in-plane direction.

Thermal contact resistance at the interfaces of two adjacent layer of the MEA is a barrier to heat transport. Fig. 10 gives the temperature distribution through out the MEA of the DMFC with different types of GDLs. Clearly, when the thermal contact resistance is considered in the model, a jump of temperature at the GDL/CL and Rib/GDL interfaces appears and hot spot is easily encountered in the region in cathode CL under channel. Temperature jump at Rib/GDL interface for the case of isotropic GDL is $2 \mathrm{~K}$, while $1.6 \mathrm{~K}$ for the anisotropic GDL. The highest temperature jump at GDL/CL interface for the case of isotropic GDL is $0.8 \mathrm{~K}$, while $1 \mathrm{~K}$ for the anisotropic GDL. Contact resistance is very sensitive to compression on the GDL. The inhomogeneous deformation of GDL from $380 \mu \mathrm{m}$ to $250 \mu \mathrm{m}$ leads to a $93 \%$ reduction of thermal contact resistance at the Rib/GDL interface, and also a significant reduction of thermal contact resistance at the GDL/CL interface. So for the case of deformed GDL, the temperature range across the MEA is smaller than the case of isotropic GDL and anisotropic GDL. The temperature jump at the Rib/GDL interface for the case of deformed GDL is about $0.15 \mathrm{~K}$, while $0.3 \mathrm{~K}$ at the GDL/CL interface. It can be temporally concluded that the compression on GDLs makes a better contact of adjacent layer of the MEA and is favorable to heat transport in the DMFC.

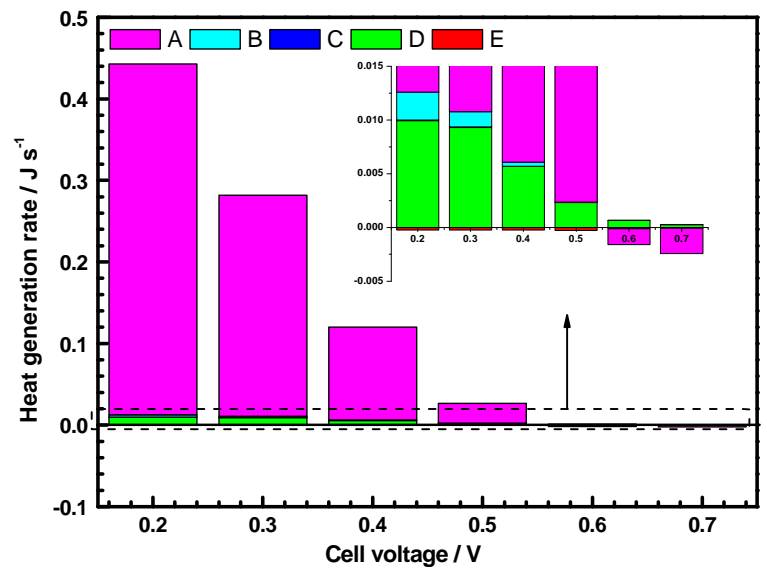

Fig. 7 Heat generation rate in the ACL due to A: anode half-reaction, $\mathrm{B}$ : ion transport, $\mathrm{C}$ : electron transport, $\mathrm{D}$ : methanol evaporation/condensation, E: water evaporation/condensation.

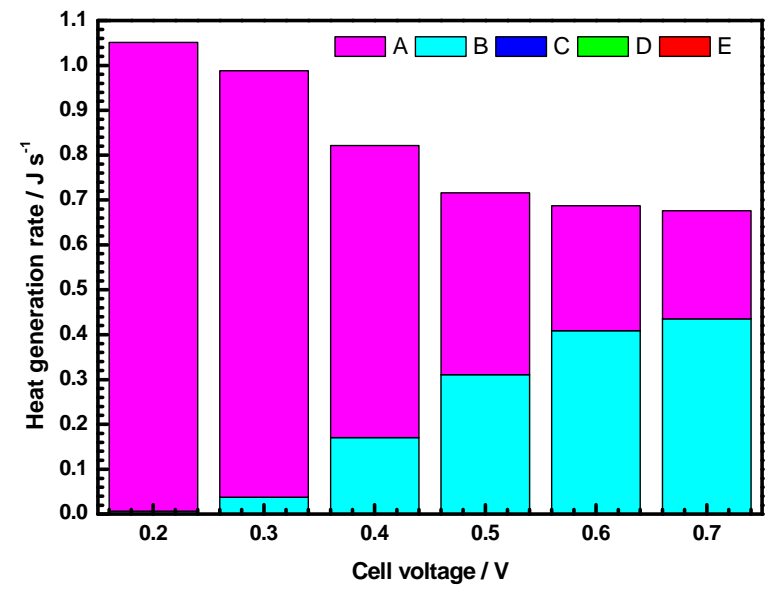

Fig. 8 Heat generation rate in the CCL due to A: anode half-reaction, B: methanol crossover, $\mathrm{C}$ : ion transport, $\mathrm{D}$ : electron transport, $\mathrm{E}$ : water evaporation/condensation.

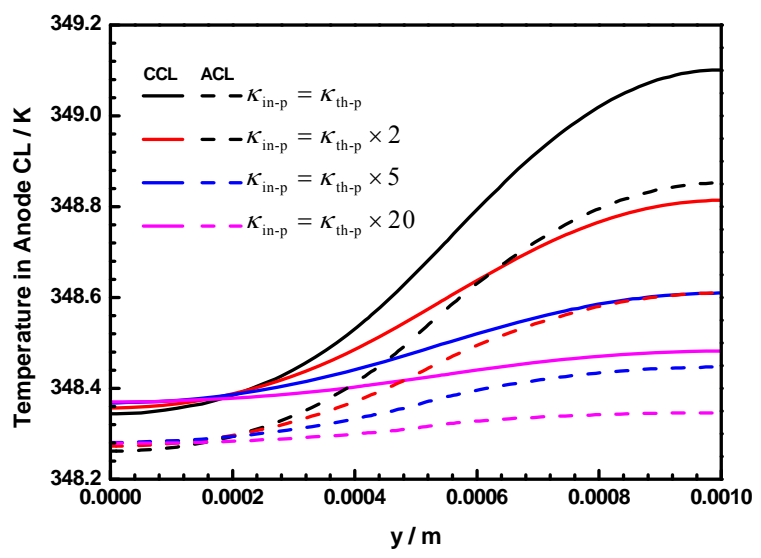

Fig. 9 Temperature distribution in anode and cathode CLs for various in-plane thermal conductivities.

Figure 11 and 12 give the temperature profiles in the anode and cathode CLs for the case of deformed GDL with different thermal contact resistance at the GDL/CL interface and Rib/GDL interface. It can be seen in Fig. 11 that the increase in thermal contact resistance at the GDL/CL interfaces leads to a significant increase in temperature in 


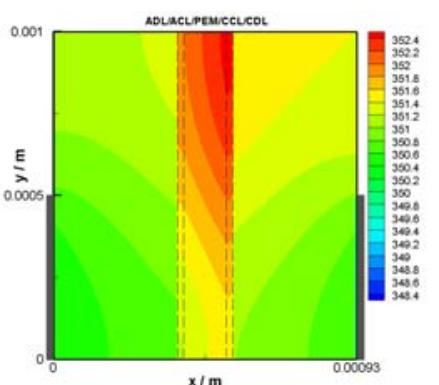

(a)

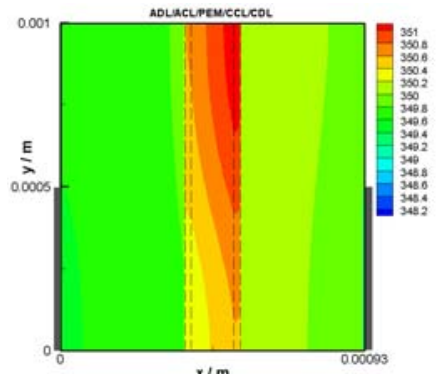

(b)

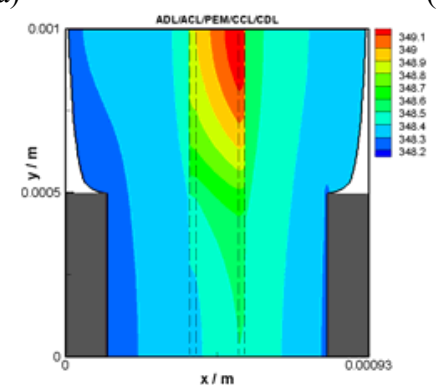

(c)

Fig. 10 Temperature distribution in the MEA with thermal contact resistance for (a) isotropic GDL, (b) anisotropic GDL and (c) deformed GDL.

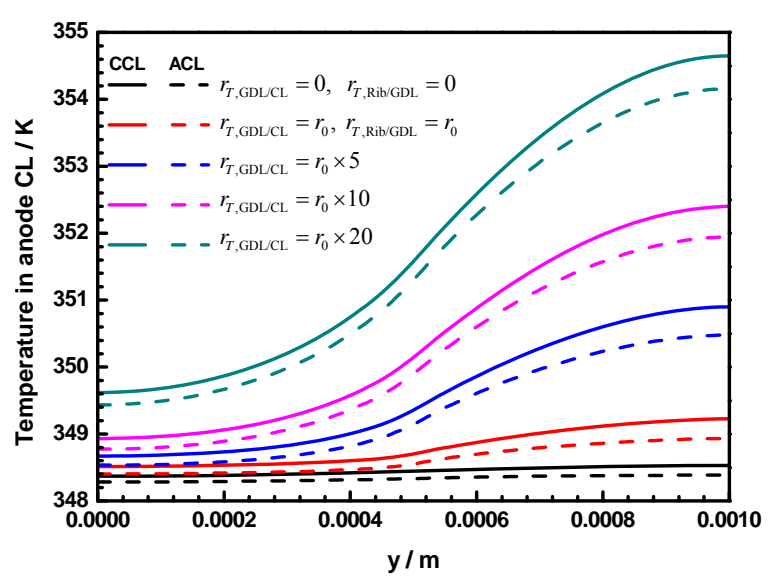

Fig. 11 Temperature distribution in anode and cathode CLs for various thermal contact resistance at the GDL/CL interface.

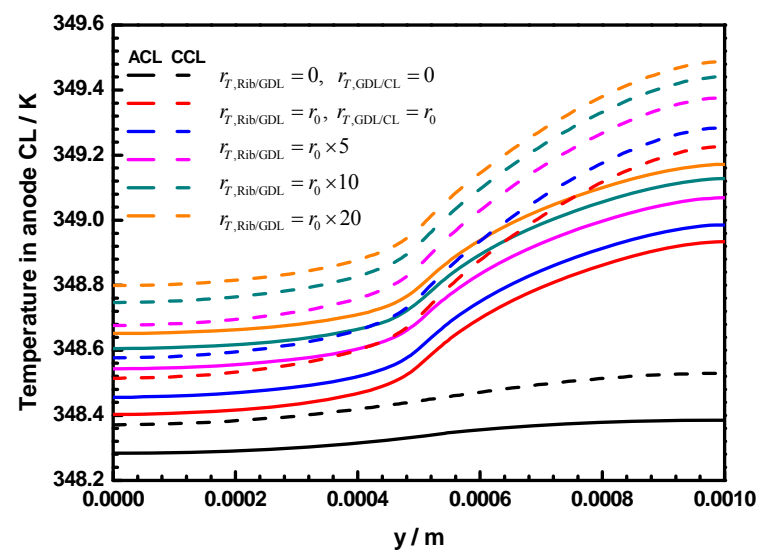

Fig. 12 Temperature distribution in anode and cathode CLs for various thermal contact resistance at the Rib/GDL interface. anode and cathode CLs, especially in the region under channel. When the thermal contact resistance increases to 20 times higher than the initial value, the highest temperature in the cathode CL increases by 6 $\mathrm{K}$. Such a big temperature range will cause severe problem in the operation of DMFC, especially for the fuel cell stack or a long time working fuel cell.

All of heat generated in the MEA transfers through the Rib/GDL interface. So the effect of thermal contact resistance at the Rib/GDL interface is investigated in the present work and the results are presented in Fig. 12. It can be seen from the figure that with the increase in thermal contact resistance at the Rib/GDL interface, temperature in anode and cathode CLs increases. However the variation of temperature, about $1 \mathrm{~K}$, is smaller than that in Fig. 11. It is because the effect of thermal contact resistance at the Rib/GDL interface is weakened by the deformation of the GDLs. As the thermal transport properties of the MEA are not changed, the profiles of temperature along the in-plane direction in the CLs almostly maintain the same gradient.

\section{CONCLUSIONS}

A two-dimensional two-phase non-isothermal model is developed for DMFCs with the anisotropy of GDLs taken into account. Heat generations from half-reactions in CLs, transport of electrons and ions, methanol crossover, and non-equilibrium evaporation/condensation of water and methanol are considered in the present work. The heat generation and transport mechanism are investigated. From the numerical results and discussions in the above sections, it can be concluded that heat flux mainly generated in anode and cathode CLs. Increase in cell current density leads to a nearly linear increase in local heat generation rate. In anode $\mathrm{CL}$, heat generation from MOR contributes the most of overall heat flux. In cathode CL, the heat flux is mainly contributed to heat release from half-reaction and methanol crossover. The other mechanisms of heat generation only share a very small portion of the overall heat flux. In-plane thermal conductivity has a great effect on temperature distribution in the MEA. However, it only has a moderate effect on the temperature difference across the MEA. Compared to the effect of in-plane thermal conductivity, the effects of thermal contact resistance at the GDL/CL interface are more significant. A 20-fold increase in thermal contact resistance at the GDL/CL interface will cause about $6 \mathrm{~K}$ increase in the highest temperature of the MEA. The effect of thermal contact resistance at the Rib/GDL interface is weakened by the deformation of GDL. The highest temperature increases by $1 \mathrm{~K}$ when thermal resistance becomes 20 times higher. So the inherent anisotropy of thermal transport properties and deformation of GDL are favorable to the thermal management of DMFC. And more efforts on the optimization of surface properties of adjacent layer of the MEA and assembly technique are still required to improve cell performance and obtain more efficient thermal management.

\section{ACKNOWLEDGEMENTS}

This work is supported by the Key Project of National Natural Science Foundation of China (No. U0934005, No.50821064).

\section{NOMENCLATURE}

\section{List of symbols}

specific area in the catalyst layer $\left(\mathrm{m}^{2} \mathrm{~m}^{-3}\right)$ concentration $\left(\mathrm{mol} \mathrm{m}^{-3}\right)$

diffusivity $\left(\mathrm{m}^{2} \mathrm{~s}^{-1}\right)$

D faraday constant, $96485 \mathrm{C} \mathrm{mol}^{-1}$

$G \quad$ Gibbs free energy $\left(\mathrm{J} \mathrm{mol}^{-1}\right)$

$h \quad$ height of channel or rib ( $\mathrm{m})$

$H \quad$ enthalpy $\left(\mathrm{J} \mathrm{mol}^{-1}\right)$ 
i electrochemical reaction rate $\left(\mathrm{A} \mathrm{m}^{-3}\right)$

I current density $\left(\mathrm{A} \mathrm{m}^{-3}\right)$

$K \quad$ absolute permeability of porous media $\left(\mathrm{m}^{2}\right)$

$k_{\mathrm{c}} \quad$ condensation rate of water $\left(\mathrm{s}^{-1}\right)$

$k_{\mathrm{e}} \quad$ evaporation rate of water $\left(\mathrm{atm}^{-1} \mathrm{~s}^{-1}\right)$

$k_{\mathrm{H}} \quad$ Henry's law constant

$k_{\mathrm{rg}}$

\section{relative permeability of gas phase}

relative permeability of liquid phase

length of the channel ( $\mathrm{m}$ )

source terms in mass conservation equations $\left(\mathrm{kg} \mathrm{m}^{-3} \mathrm{~s}^{-1}\right)$

molecular weight $\left(\mathrm{kg} \mathrm{mol}^{-1}\right)$

electro-osmotic drag coefficient

molar flux $\left(\mathrm{mol} \mathrm{m} \mathrm{s}^{-1}\right)$

pressure $\left(\mathrm{p}_{\mathrm{a}}\right)$

capillary pressure $\left(\mathrm{p}_{\mathrm{a}}\right)$

switch factor

gas constant $\left(\mathrm{J} \mathrm{mol}^{-1} \mathrm{~K}^{-1}\right)$

source term in species conservation equations $\left(\mathrm{mol} \mathrm{m}^{-3} \mathrm{~s}^{-1}\right)$

interfacial transfer rate of water $\left(\mathrm{mol} \mathrm{m}^{-3} \mathrm{~s}^{-1}\right)$

liquid saturation

temperature $(\mathrm{K}$ )

superficial velocity vector $\left(\mathrm{m} \mathrm{s}^{-1}\right)$

thermodynamic equilibrium voltage $(\mathrm{V})$

cell voltage $(\mathrm{V})$

\section{Greek}

$\alpha \quad$ transfer coefficient

$\gamma \quad$ reaction order

$\varepsilon \quad$ porosity of the porous media

$\kappa \quad$ thermal conductivity $\left(\mathrm{W} \mathrm{m}^{-1} \mathrm{~K}^{-1}\right)$

$\mu \quad$ viscosity $\left(\mathrm{kg} \mathrm{m}^{-1} \mathrm{~s}^{-1}\right)$

$\theta_{\mathrm{c}} \quad$ contact angle $\left({ }^{\circ}\right)$

$\rho \quad$ density $\left(\mathrm{kg} \mathrm{m}^{-3}\right)$

$\sigma \quad$ interfacial tension $\left(\mathrm{N} \mathrm{m}^{-1}\right) /$ Conductivity $\left(\Omega^{-1} \mathrm{~m}^{-1}\right)$

\section{Superscripts}

$\begin{array}{ll}\text { eff } & \text { effective value } \\ \text { in } & \text { inlet of the flow channel } \\ \text { mem } & \text { membrane } \\ \text { ref } & \text { reference value } \\ \text { sat } & \text { saturated }\end{array}$

\section{Subscripts}

$\begin{array}{ll}\mathrm{a} & \text { anode } \\ \mathrm{c} & \text { cathode } \\ \mathrm{e}^{-} & \text {electrons } \\ \mathrm{H}^{+} & \text {protons } \\ \mathrm{g} & \text { gas phase } \\ \mathrm{l} & \text { liquid phase } \\ \mathrm{m} & \text { the membrane phase } \\ \mathrm{N} & \text { Nafion phase } \\ \mathrm{O}_{2} & \text { oxygen } \\ \mathrm{s} & \text { the solid phase } \\ \mathrm{WV} & \text { water vapor } \\ \mathrm{MV} & \text { methanol vapor }\end{array}$

\section{REFERENCES}

Acres G. J. K., 2001, "Recent advances in fuel cell technology and its applications," J. Power Sources 100(1-2), 60-66. doi:10.1016/S0378-7753(01)00883-7

Ahmed D. H., Sung H. J. and Bae J., 2008, "Effect of GDL permeability on water and thermal management in PEMFCs - I. Isotropic and anisotropic permeability," Int. J. Hydrogen Energy 33(14), 3767-3785.

doi:10.1016/j.ijhydene.2008.04.024

Ahmed D. H., Sung H. J. and Bae J., 2008, "Effect of GDL permeability on water and thermal management in PEMFCs - II. Clamping force," Int. J. Hydrogen Energy 33(14), 3786-3800. doi:10.1016/j.ijhydene.2008.04.023

Bapat C. J. and Thynell S. T., 2007, "Anisotropic heat conduction effects in proton-exchange membrane fuel cells," J. Heat Transfer 129(9), 1109-1118. doi: $10.1115 / 1.2712478$

Bapat C. J. and Thynell S. T., 2008, "Effect of anisotropic electrical resistivity of gas diffusion layer (GDLs) on current density and temperature distribution in a polymer elelctrolyte membrane (PEM) fuel cell," J. Power Sources 185(1), 428-432.

doi:10.1016/j.jpowsour.2008.06.016

Basu S., Renfro M. W., Gorgun H. and Cetegen B. M., 2006, "In situ simultaneous measurements of temperature and water partial pressure in a PEM fuel cell under steady state and dynamic cycling," J. Power Sources 159(2), 987-994.

doi:10.1016/j.jpowsour.2005.11.091

Chen R. and Zhao T. S., 2005, "Mathematical modeling of a passivefeed DMFC with heat transfer effect," J. Power Sources 152(1), 122130.

doi:10.1016/j.jpowsour.2005.02.088

Chen R., Zhao T. S., Yang W. W. and Xu C., 2008, "Two-dimensional two-phase thermal model for passive direct methanol fuel cells," $J$. Power Sources 175(1), 276-287.

doi:10.1016/j.jpowsour.2007.09.086

Coppo M., Siegel N. P. and Spakovsky M. R. v., 2006, "On the influence of temperature on PEM fuel cell operation," J. Power Sources 159(1), 560-569.

doi:10.1016/j.jpowsour.2005.09.069

David N. A., Wild P. M., Hu J. and Djilali N., 2009, "In-fibre Bragg grating sensors for distributed temperature measurement in a polymer electrolyte membrane fuel cell," J. Power Sources 192(2), 376-380. doi:10.1016/j.jpowsour.2009.03.021

Divisek J., Fuhrmann J., Gartner K. and Jung R., 2003, "Performance modeling of a direct methanol fuel cell," J. Electrochem. Soc. 150(6), A811-A825.

doi:10.1149/1.1572150

Dohle H., Mergel J. and Stolten D., 2002, "Heat and power management of a direct-methanol-fuel-cell (DMFC) system," J. Power Sources 111(2), 268-282.

doi:10.1016/S0378-7753(02)00339-7

Dyer C. K., 2002, "Fuel cells for portable applications," J. Power Sources 106(1-2), 31-34. doi:10.1016/S0378-7753(01)01069-2

He Y. L., Li X. L., Miao Z. and Liu Y. W., 2009, "Two-phase modeling of mass transfer characteristics of a direct methanol fuel cell," Applied Thermal Engineering 29(10), 1998.

doi:10.1016/j.applthermaleng.2008.10.004 
Hottinen T. and Himanen O., 2007, "PEMFC temperature distribution caused by inhomogeneous compression of GDL," Electrochem. Commun. 9(5), 1047-1052.

doi:10.1016/j.elecom.2006.12.018

Hottinen T., Himanen O., Karvonen S. and Nitta I., 2007, "Inhomogeneous compression of PEMFC gas diffusion layer Part II. Modeling the effect," J. Power Sources 171(1), 113-121. doi:10.1016/j.jpowsour.2006.10.076

Ju H., 2009, "Investigation of the effects of the anisotropy of gasdiffusion layers on heat and water transport in polymer electrolyte fuel cells," J. Power Sources 191(2), 259-268.

doi:10.1016/j.jpowsour.2009.01.103

Li X. L., He Y. L., Yin B. H., Miao Z. and Li X. Y., 2008, "Exergy flow and energy utilization of direct methanol fuel cells based on a mathematic model," J. Power Sources 178(1), 344-352.

doi:10.1016/i.jpowsour.2007.08.019

Liu W. P. and Wang C. Y., 2007, "Modeling water transport in liquid feed direct methanol fuel cells," J. Power Sources 164(1), 189-195. doi:10.1016/j.jpowsour.2006.10.047

Matamoros L. and Bruggemann D., 2006, "Simulation of the water and heat management in proton exchange membrane fuel cells," J. Power Sources 161(1), 203-213.

doi:10.1016/j.jpowsour.2006.03.078

Meng H., 2006, "A three-dimensinal PEM fuel cell model with consistent treatment of water transport in MEA," J. Power Sources 162(1), 426-435.

doi:10.1016/j.jpowsour.2006.07.022

Miao Z., He Y. L. and Zou J. Q., 2010, "Modeling the effect of anisotropy of gas diffusion layer on transport phenomena in a direct methanol fuel cell," J. Power Sources 195(11), 3693-3708.

doi:10.1016/i.jpowsour.2009.12.048

Miao Z., He Y. L., Li X. L. and Zou J. Q., 2008, "A two-dimensional two-phase mass transport model for direct methanol fuel cells adopting a modified agglomerate approach," J. Power Sources 185(2), 12331246.

doi:10.1016/j.jpowsour.2008.06.007

Murgia G., Pisani L., Shukla A. K. and Scott K., 2003, "A numerical model of a liquid-feed solid polymer electrolyte DMFC and its experimental validation," J. Electrochem. Soc. 150(9), A1231-A1245. doi:10.1149/1.1596951

Nitta I., Himanen O. and Mikkola M., 2008, "Contact resistance between gas diffusion layer and catalyst layer of PEM fuel cell," Electrochemistry Communications 10(1), 47-51.

doi:10.1016/j.elecom.2007.10.029

Nitta I., Himanen O. and Mikkola M., 2008, "Thermal Conductivity and Contact Resistance of Compressed Gas Diffusion Layer of PEM Fuel Cell," Fuel Cells 8(2), 111-119.

doi:10.1002/fuce.200700054

Nitta I., Hottinen T., Himanen O. and Mikkola M., 2006, "Inhomogeneous compression of PEMFC gas diffusion layer Part I. Experimental," J. Power Sources 171(1), 26-36. doi:10.1016/i.jpowsour.2006.11.018

Nitta I., Karvonen S., Himanen O. and Mikkola M., 2008, "Modelling the Effect of Inhomogeneous Compression of GDL on Local Transport Phenomena in a PEM Fuel Cell," Fuel Cells 8( 6), 410-421. doi:10.1002/fuce. 200700058

Nordlund J. and Lindbergh G., 2002, "A model for the porous direct methanol fuel cells anode," J. Electrochem. Soc. 149(9), A1107-A1113. doi:10.1149/1.1494824

Oliveira V. B., Falcao D. S., Rangel C. M. and Pinto A. M. F. R., 2008, "Heat and mass transfer effects in a direct methanol fuel cell: A 1D model," Int. J. Hydrogen Energy 33(14), 3818-3828.

doi:10.1016/j.ijhydene.2008.04.032

Pasaogullari U., Mukherjee P. P., Wang C.-Y. and Chen K. S., 2007, "Anisotropic heat and water transport in a PEFC cathode gas diffusion layer," J. Electrochem. Soc. 154(8), B823-B834. doi:10.1149/1.2745714

Sadeghi E., Bahrami M. and Djilali N., 2008, "Analytic determination of the effective thermal conductivity of PEM fuel cell gas diffusion layers," J. Power Sources 179(1), 200-208.

doi:10.1016/j.jpowsour.2007.12.058

Song D., Wang Q., Liu Z., Navessin T., Eikerling M. and Holdcroft S., 2004, "Numerical optimization study of the catalyst layer of PEM fuel cell cathode," J. Power Sources 126(1-2), 104-111.

doi:10.1016/j.jpowsour.2003.08.043

Um S., Wang C. Y. and Chen K. S., 2000, "Computational fluid dynamics modelling of proton exchange membrane fuel cells," $J$. Electrochem. Soc. 147(12), 4485-4493.

doi:10.1149/1.1394090

Vie P. J. S. and Kjelstrup S., 2004, "Thermal conductivities from temperature profiles in the polymer electrolyte fuel cell," Electrochim. Acta 49(7), 1069-1077.

doi:10.1016/j.electacta.2003.10.018

Wang Q., Eikerling M., Song D. and Liu Z., 2004, "Structure and performance of different types of agglomerates in cathode catalyst layers of PEM fuel cells," J. Electroanal. Chem. 573(1), 61-69. doi:10.1016/i.jelechem.2004.06.022

Wang Z. H. and Wang C. Y., 2003, "Mathematical modeling of LiquidFeed Direct Methanol Fuel Cells," J. Electrochem. Soc. 150(4), A508A519.

doi:10.1149/1.1559061

Yang W. W. and Zhao T. S., 2007, "A two-dimensional two-phase mass transport model for liquid-feed DMFCs," Electrochim. Acta 52(20), 6125-6140.

doi:10.1016/j.electacta.2007.03.069

Yang W. W., Zhao T. S. and He Y. L., 2008, "Modeling of coupled electron and mass transport in anisotropic proton-exchange membrane fuel cell electrodes," J. Power Sources 185(2), 765-775. doi:10.1016/j.jpowsour.2008.06.100 